\title{
Treatment of Hemp Fibres for use in Rotational Moulding.
}

\author{
Maria A. S. Oliveira ${ }^{\mathrm{a} *}$, Kim L. Pickering ${ }^{\mathrm{a}}$, Tom Sunny ${ }^{\mathrm{a}}$, Richard J. T. Lin ${ }^{\mathrm{b}}$. \\ ${ }^{a}$ Division of Health, Engineering, Computing and Science (HECS), University of Waikato, \\ Hamilton, New Zealand. \\ ${ }^{b}$ Department of Mechanical Engineering, Auckland University, Auckland, New Zealand. \\ *maso_oliveira@yahoo.com.br
}

Abstract: The benefit of using alkali-treated hemp fibre as the reinforcement for rotationally moulded polyethylene composites was evaluated in this research. Untreated and alkali-treated hemp fibre were characterised using different techniques such as scanning electron microscopy (SEM), thermal analysis, and Fourier transform infrared spectroscopy (FT-IR). These techniques showed that the alkali treatment removed non-cellulosic components from hemp fibres, which improved their separation and thermal resistance. Composites with alkali-treated fibre resisted the exposure to elevated temperatures for prolonged periods (characteristic of the rotational moulding process) with no apparent signs of thermal degradation, unlike when untreated fibre was used. The effect of using maleic anhydride grafted polyethylene (MAPE) as a coupling agent was also investigated. The addition of 3 wt\% MAPE improved the properties tensile strength and Young's modulus of composites with treated hemp fibre, which was attributed to better fibre-matrix adhesion. Different fibre contents were assessed in this research to produce rotationally moulded composites; a poor fibre distribution was observed above $5 \mathrm{wt} \%$ fibre content, which resulted in low tensile strength and Young's modulus.

Keywords: Hemp fibre; alkali treatment; MAPE; polyethylene; rotational moulding. 


\section{Introduction}

Rotational moulding is used to manufacture hollow plastic products in the absence of any applied pressure. The process generally consists of submitting a polymer powder into a mould, which rotates slowly about one or two perpendicular axes, and heated until the powder forms a homogeneous polymer melt and finally cooled until polymer solidification occurs $[1,2]$. Rotational moulding has significant advantages over other manufacturing methods such as low investment costs (the moulds are inexpensive) as well as flexibility (the process can handle complex shapes, a wide range of sizes and thicknesses of moulds). Polyethylene (PE) is broadly used in rotational moulding, due to its low melting point, good thermal stability and low cost. However, PE has modest mechanical properties in comparison with other materials, which prevent its use in many applications [3].

Natural fibres have been suggested as a reinforcement to improve the mechanical and physical properties of rotationally moulded polyethylene [4,5]. Indeed, natural fibres are a potential replacement for glass fibre in composites, generally due to their high specific stiffness and strength. Natural fibres also have advantages over glass fibre, including lower cost, lower density, and they are a renewable resource [6-8]. However, only modest results in mechanical properties have been reported using natural fibres as a reinforcement in rotational moulding $[4,5]$. This poor reinforcement is attributed to fibre agglomeration and therefore, poor distribution within the final composite. Furthermore, cellulose fibres have poor interfacial bonding with the non-polar thermoplastic matrices used in rotational moulding. This poor adhesion limits stress transfer from the applied force to the fibres, resulting in low mechanical properties [9].

Extensive research has been carried out using a variety of techniques to improve interfacial bonding in polymer-natural fibres composites [9-11]. These approaches include chemical, physical and biological treatments and the use of coupling agents. Among chemical treatments, alkali treatment has been reported as the most efficient method to remove components from natural fibres such as hemicellulose, lignin and pectin. The removal of these cementing materials exposes cellulose and increases surface roughness and area provided for interfacial bonding [12-14]. The cellulose $\mathrm{OH}$ groups exposed on the fibre surface react with coupling agents such as maleic anhydride, providing a better bonding between fibre and matrix. In the case of MAPE (Maleic anhydride grafted polyethylene), the maleic anhydride groups 
react with the hydroxyl groups by covalent or hydrogen bonds, whereas the polyethylene chain on MAPE bonds with the polyethylene matrix by entanglement $[15,16]$. Few attempts have been made using MAPE in rotationally molded composites. These studies reported that MAPE improved tensile strength and Young's modulus of rotationally moulded PE composites reinforced with natural fibre due to a better fibre-matrix adhesion $[17,18]$.

Industrial hemp fibre has recently gained more attention because of its high specific Young's modulus and tensile strength and local availability in New Zealand [6]. However, no previous work has been reported in the literature for incorporating hemp fibre within rotational moulding. The use of natural fibres in rotationally moulded composites could allow the production of more sustainable products, with good mechanical properties at low cost. This research assessed the potential of hemp fibres as a reinforcement to rotationally moulded polyethylene composites. A combination of alkali treatment and a coupling agent to improve fibre-matrix adhesion was used. As the interface is crucial to both the physical and mechanical properties of composites, the combination of these methods was predicted to improve mechanical properties of rotationally moulded composites.

\section{Materials and Methods}

\section{Materials}

Industrial hemp fibre (Cannabis Sativa L.), was used as reinforcement was grown in Hawkes Bay, New Zealand. The fibres were received in piles and manually stripped from their stalks. The matrix used was low medium density polyethylene (LMDPE), VX567, in powder form, $\left(\right.$ MFI $=6 \mathrm{~g} / 10 \mathrm{~min}$, density $\left.=0.935 \mathrm{~g} / \mathrm{cm}^{3}\right)$, donated by VPLAS LTDA, New Zealand. The coupling agent used was polyethylene grafted maleic anhydride (MAPE), 456632, (Viscosity $=1,700-4,500 \mathrm{cP}$ at $140^{\circ} \mathrm{C}$, Saponification value $=30-40 \mathrm{mg} \mathrm{KOH} / \mathrm{g}$ ), obtained from SIGMA-ALDRICH. $\mathrm{NaOH}$ and $\mathrm{Na}_{2} \mathrm{SO}_{3}$ were obtained from MERCK (both 98\% purity).

\section{Alkali Treatment}

Industrial hemp fibre was treated with a solution of $5 \mathrm{wt} \% \mathrm{NaOH} / 2 \mathrm{wt} \% \mathrm{Na}_{2} \mathrm{SO}_{3}$, with fibre/solution ratio 1:8 (by weight). The hemp fibres and the alkali solution were placed in canisters and processed at $120^{\circ} \mathrm{C}$ for 60 minutes under high pressure using a laboratory-scale pulp digester. Once the digestion process was completed, the canisters were cooled to about 
$30-40^{\circ} \mathrm{C}$, and the fibres were removed. Treated fibres were washed in clean water for 10 minutes and dried at $80^{\circ} \mathrm{C}$ for 48 hours.

\section{Tensile Testing of Single Fibre}

The tensile strength and Young's modulus of hemp fibres (untreated and treated) were determined according to the ASTM D3379-75 "Standard Test Method for Tensile Strength and Young's Modulus for High-Modulus Single Filament Materials". Hemp fibres were separated from their bundles in a single fibre and placed on a $2 \mathrm{~mm}$ thick cardboard with a $2 \mathrm{~mm}$ gauge length. An Olympus BX60 metallurgical microscope was used to confirm that only a single fibre was present on each card. The fibre diameter was measured at four different locations along the fibre length. The mounted fibres were tensile tested to failure in an Instron-4204 tensile testing machine at a rate of $0.5 \mathrm{~mm} / \mathrm{min}$ using a $10 \mathrm{~N}$ load cell.

\section{Scanning Electron Microscopy}

Scanning electron microscopy (SEM) was used to analyse the fibre-matrix interface of fractured cryogenic surfaces of composites. The samples were placed on aluminium stubs using carbon tape and then coated with platinum plasma. The images were obtained using a Hitachi S-4100 field emission scanning electron microscope at $5 \mathrm{kV}$.

\section{Thermogravimetric Analysis}

Thermogravimetry (TG) and derivative thermogravimetry (DTG) curves were obtained to study the thermal behaviour of hemp fibre before and after the treatment. Samples of untreated and treated hemp weighing 2- 3 mg were analysed using a PerkinElmer STA 8000. The analysis was performed in a dynamic mode, heating from $40^{\circ} \mathrm{C}$ to $800^{\circ} \mathrm{C}$ at $10^{\circ} \mathrm{C} / \mathrm{min}$ in an air purged at $50 \mathrm{~mL} / \mathrm{min}$.

\section{Fourier Transform Infrared Spectroscopy}

Fourier Transform Infrared Spectroscopy (FT-IR) analysis was used to identify changes in the hemp fibre constituents after the treatment. FT-IR measurements were performed using a PerkinElmer Spectrum One spectrometer with transmission mode from 4000 to $400 \mathrm{~cm}^{-1}$, and 20 scans were taken for each sample with a resolution of $4 \mathrm{~cm}^{-1}$. To prepare the samples, grounded dried fibre and $\mathrm{KBr}$ (0.8 mg fibre per $400 \mathrm{mg} \mathrm{KBr}$ ) were pressed into pellets. 


\section{Composite Preparation by Rotational Moulding}

Initially, untreated and treated hemp fibres were chopped into fibre lengths of 1-3 mm using a granulator and then dried in an oven at $100^{\circ} \mathrm{C}$ for 24 hours. The polyethylene and the MAPE coupling agent used in the composites were also dried for the same length of time. Hemp fibre was mixed with PE and in selected cases with MAPE, for five minutes using a Waring Commercial laboratory blender. The composition details are shown in Table 1.

A monoaxial rotational moulder machine was used for composite processing at a rate of $20 \mathrm{rpm}$. A square "box-shaped" mould was used with internal dimensions of $100 \mathrm{~mm} \mathrm{x}$ $100 \mathrm{~mm}$ x $140 \mathrm{~mm}$. In all cases, a weight of $350 \mathrm{~g}$ of material (mix of hemp fibre and PE) was loaded into the mould. Mould rotation was initiated before heating. The oven temperature was set to $240^{\circ} \mathrm{C}$ (maximum temperature available in the oven), and the material was heated for approximately 30 minutes until the air temperature in the mould had reached the peak internal air temperature (PIAT) of $190^{\circ} \mathrm{C}$. At this stage, the oven was turned off and its door was opened. A fan was placed in front of the oven to assist the cooling and the product was demoulded at $40^{\circ} \mathrm{C}$.

\section{Optical Microscopy}

Optical microscopy images of all the composites were obtained to analyse their surface aesthetics. The images were taken with $6.5 \mathrm{x}$ magnification, using a WILD M3B stereomicroscope with a Nikon camera (Digital Sight DSU1).

\section{Tensile Testing}

Composite samples for the tensile test were placed in a conditioning chamber at $23^{\circ} \mathrm{C}$ $\pm 3^{\circ} \mathrm{C}$ and $50 \% \pm 5 \%$ relative humidity for 48 hours. The samples were then tested according to the ASTM D638-14 "Standard Method for Tensile Properties of Plastics", using an INSTRON-4204 tensile testing machine fitted with a $5 \mathrm{KN}$ load cell and operated at a rate of $1 \mathrm{~mm} / \mathrm{min}$. An Instron extensometer, gauge length $20 \mathrm{~mm}$, was used to measure the composite strain. Seven specimens of each type of composite were tested to failure. 


\section{Statistics}

Statistics analysis was performed to compare the mean of tensile strength and Young's modulus results using the Student t-test paired two-sample for means, with 95\% confidence interval.

\section{Results and Discussion}

\section{Single Fibre Tensile Properties}

Alkali treatment was used to remove non-cellulosic components such as lignin, pectin and hemicellulose from hemp fibres. The results showed a reduction of nearly $24 \%$ in hemp fibre diameter after alkali treatment (Table 2); fibre diameter reduction is consistent with the removal of non-cellulosic materials [10].

The tensile strength of single hemp fibres has unchanged after the treatment as confirmed by one-tailed Student's t-test, which suggests that no significant degradation has occurred to the cellulose microfibrils during the alkali treatment.

\section{Scanning Electron Microscopy}

The SEM micrograph of untreated hemp fibre in Fig. 1a shows that hemp fibres were initially in bundles. However, after the alkali treatment, the hemp fibres were separated from their bundles, as can be seen in Fig. 1b. This outcome is consistent with the literature, which reports the treatment of cellulosic fibres by sodium hydroxide $(\mathrm{NaOH})$ as an efficient method to separate single fibres from their bundles by removing non-cellulosic materials including pectin, lignin, and hemicellulose $[7,19]$. According to previous work, the alkali treatment interrupts the $\mathrm{OH}$ bonding in the fibre network structure leading to the separation of the interfibrillar regions from the cellulose fibres [20]. This fibre separation could enable better fibre dispersion within the fabricated composites. It has been shown that good fibre dispersion within the composites promotes good interfacial bonding, reducing voids by ensuring that fibres are entirely surrounded by the matrix, improving the properties of short fibre composites [21]. 


\section{Thermogravimetric Analysis}

The thermal degradation of hemp fibre can be identified by three weight-loss stages in TGA thermograms, as shown in Fig. 2. The first stage of weight loss from $30-100^{\circ} \mathrm{C}$ is due to the release of moisture content of the fibre. The second weight loss from $200-360^{\circ} \mathrm{C}$ is due to the thermal degradation of amorphous materials such as hemicellulose, lignin and pectin, followed by cellulose $[27,23]$. The final stage of weight loss ranging from $360-500^{\circ} \mathrm{C}$ is due to the thermal degradation of cellulose and remaining lignin [28]. The DTG curves showed that the treated fibre started thermal degradation at all the different stages at consistently higher temperatures than untreated fibre, indicating that the alkali treatment improved the fibre thermal resistance. Untreated fibre degrades first due to less unstable components as previously mentioned, whereas, in treated fibres, the thermal decomposition mainly occurred on the cellulose [27]. The onset temperature of thermal degradation of the treated fibre changed to a higher temperature as a result of a higher content of crystalline cellulose, which contains strong intramolecular and intermolecular hydrogen bonds, requiring high energy to be broken down [29].

\section{Fourier Transform Infrared Spectroscopy}

FT-IR allowed the assessment of the variation of hemp fibre chemical composition with the alkali treatment (see Fig. 3). The broad absorption band observed in $3397 \mathrm{~cm}^{-1}$ is related to hydroxyl $(\mathrm{OH})$ groups of absorbed moisture. This peak appeared weaker in intensity after the alkali treatment, indicating that moisture was removed [30]. The vibration peak at $2889 \mathrm{~cm}^{-1}$ has not changed after the treatment as it relates to $\mathrm{C}-\mathrm{H}$ aliphatic group of all the hydrocarbon constituents of natural fibres. One of the most visible differences between the spectra is the modification of the peak at $1740 \mathrm{~cm}^{-1}$, which is related to the $\mathrm{C}=\mathrm{O}$ stretching of acetyl or carboxylic acid groups of hemicellulose in untreated fibres. This peak disappeared after the treatment as a result of the removal of hemicellulose from hemp fibres. [24,31]. Another difference between the spectra shown in Fig. 3 is the reduction of the peak at $1630 \mathrm{~cm}^{-1}$, which corresponds to $\mathrm{C}=\mathrm{C}$ and $\mathrm{C}=\mathrm{O}$ stretching of the aromatic ring of lignin. Fig. 3 also shows that the peak at $1232 \mathrm{~cm}^{-1}$, which corresponds to the C-O stretching vibration in lignin [31,32] disappeared after the treatment. These results support the reduction of lignin content from hemp fibre after the alkali treatment. 


\section{Rotational Moulding}

Rotationally moulded composites were initially produced with $5 \mathrm{wt} \%$ fibre content to assess the effect of the alkali treatment with the addition of MAPE. The external surfaces of these composites were studied by optical microscopy (Fig. 4). Composites with untreated fibre were a dark brownish colour due to thermal degradation, as shown in Fig. 4b and Fig. 4d. Thermal degradation was not obvious for composites reinforced with treated fibre at the same content of $5 \mathrm{wt} \%$ (Fig. 4a and Fig. 4c). This result supports the earlier finding that the alkali treatment improved the hemp fibres thermal resistance, which assisted them in withstanding the prolonged cycle of rotational moulding. The images obtained also showed a few pores on the surface of composites produced with treated fibre (Fig 4a and Fig 4c), whereas many pores were observed on composites produced with untreated fibre (Fig. 4b and Fig. 4d). Greater porosity in composites with untreated fibre was caused by the release of volatiles during the thermal degradation of amorphous components present in untreated hemp fibre, such as hemicellulose and lignin. These components together represent about $20 \%$ of the chemical composition of hemp fibres [33]. As showed previously by TGA analysis, the alkali treatment increased the thermal resistance of hemp fibre from $220^{\circ} \mathrm{C}$ to $280^{\circ} \mathrm{C}$ due to the removal of these amorphous components.

Rotationally moulded composites were attempted with 2.5, 5, 7.5 and $10 \mathrm{wt} \%$ of treated hemp fibre and $3 \mathrm{wt} \%$ MAPE as shown in Fig. 5. The details of their compositions are described in Table 1. Fibre agglomeration increased drastically above $5 \mathrm{wt} \%$ fibre content as can be seen in Fig. 5; composites with $10 \mathrm{wt} \%$ fibre content had insufficient consolidation for tensile testing. Tensile strength and Young's modulus of all successfully rotationally moulded composites were assessed. Composites produced with treated hemp fibre obtained significant improvements of about 50\% in strength and Young's modulus compared to composites with untreated fibre, as shown in Fig. 6. The lower mechanical properties of composites produced with untreated fibre compared to composites with treated fibres was possibly due to a combination of higher porosity caused by thermal degradation, inferior fibre distribution and lower interfacial strength with the matrix. The combination of these factors weakens the load transfer by the matrix to the fibres, resulting in low mechanical properties. On the other hand, alkali-treated fibres were separated from their bundles after the removal of non-cellulosic materials, which increased the effective area available for wetting by the matrix. Previous 
researches have attributed the enhancement in mechanical properties of composites with alkalitreated fibre to an improved interface between matrix and fibre after the treatment $[34,14]$. The addition of MAPE in composites with $5 \mathrm{wt} \%$ treated fibre increased their tensile strength and Young's modulus by about $25 \%$ and $20 \%$, respectively $(\mathrm{p}=0.013)$. This result was related to a better fibre-matrix adhesion obtained by using a combination of alkali treatment and MAPE. This improvement in interfacial bonding allows efficient stress propagation from the matrix to the fibre. In general, the mechanical performance of short fibre reinforced composites depends amongst other factors, on an effective interfacial stress transfer between fibre and matrix $[27,35]$. Composites with 2.5 and $5 \mathrm{wt} \%$ of alkali-treated fibre and MAPE maintained the same tensile strength as polyethylene, whereas tensile strength was reduced in all the other composites. The highest Young's modulus amongst the reinforced composites was found for the composites with $5 \mathrm{wt} \%$ treated fibre content and MAPE, which was probably due to better fibre distribution. As the fibre content increased from $5 \mathrm{wt} \%$ to $7.5 \mathrm{wt} \%$, there was a reduction of about $9 \%$ in tensile strength $(\mathrm{p}=0.04)$. This reduction is probably due to the increase in fibre agglomeration seen above $5 \mathrm{wt} \%$ fibre content (Fig. 5).. The low-shear and pressure characteristics of rotational moulding limit the amount of reinforcement that can be incorporated into rotationally moulded composites. In fact, fibre agglomeration/segregation and void formation are commonly associated with low mechanical properties in fibre reinforced composites produced by rotational moulding [36-38].

SEM micrographs of the fracture surfaces of the highest performing composite, 5TM, were compared with those for 5T. Fewer fibre pull-outs (circles) and signs of fibre-matrix debonding (arrows) were observed for 5TM samples (Fig. 7a) compared with 5T samples (Fig. 7c). This behaviour indicates a weak interfacial adhesion between fibre and matrix without MAPE since the fibres cannot support the applied load and are extracted mechanically. Furthermore, hemp fibres were attached to the polymer matrix in sample 5TM, which indicates a good interface between them (Fig. 7b). In contrast, there was a poor interface between the fibre surface and matrix for sample 5T (Fig. 7d). This result can be explained by the addition of MAPE which the carbonyl groups reacts by chemical bonding with the hydroxyl groups exposed after the alkali treatment on the fibre surface, whereas MAPE polymer chain entangles with the polymer matrix, thus improving the interfacial bonding between them $[39,40]$. 


\section{Conclusions}

As seen in previous research, alkali treatment removed non-cellulosic material such as lignin and hemicellulose, which was supported by FT-IR results. This is consistent with the reduction of fibre diameter and the improvement in fibre separation as observed by SEM. Their removal also improved the fibre resistance to thermal degradation as shown by thermal analyses. It was observed that composites with alkali treated fibre were also more resistant to thermal degradation during the rotational moulding process; composites with untreated hemp fibre showed signs of thermal degradation, which resulted in low tensile strength and Young's modulus.

The highest tensile strength and Young's modulus amongst all the reinforced composites tested was found for the sample with a combination of $5 \mathrm{wt} \%$ alkali-treated fibre and MAPE. This was attributed to better fibre-matrix adhesion when using the coupling agent and due to a uniform fibre distribution within the composite at $5 \mathrm{wt} \%$ fibre content. SEM images suggested that the alkali treatment combined with MAPE improved fibre-matrix adhesion. Any improvement in the mechanical properties was observed with the addition of hemp fibre in rotationally moulded composites, in comparison to pure polyethylene; $5 \mathrm{wt} \%$ of fibre was probably an insufficient content to act as reinforcement to PE. However, above $5 \mathrm{wt} \%$ fibre content, a more inferior fibre distribution was observed, resulting in higher porosity and even lower mechanical properties. These results highlight the need for techniques to improve fibre distribution and polymer sintering in rotationally moulded composites; these topics will be subject for future study.

\section{References}

1. Crawford RJ (2012) Practical guide to rotational moulding. Smithers Rapra, Belfast, UK

2. Crawford RJ, Throne JL (2001) Rotational molding technology. William Andrew, Belfast, UK

3. Liu S-J, Peng K-M (2010) Rotational molding of polycarbonate reinforced polyethylene composites: Processing parameters and properties. Polym Eng Sci 50 (7):1457-1465

4. López-Bañuelos RH, Moscoso FJ, Ortega-Gudiño P, Mendizabal E, Rodrigue D, GonzálezNúñez R (2012) Rotational molding of polyethylene composites based on agave fibers. Polym Eng Sci 52 (12):2489-2497 
5. Wang B, Panigrahi S, Tabil L, Crerar WJ (2007) Pre-treatment of flax fibers for use in rotationally molded biocomposites. J Reinf Plast Compos 26 (5):447-463

6. Pickering KL, Efendy MGA, Le TM (2016) A review of recent developments in natural fibre composites and their mechanical performance. Composites, Part A 83:98-112

7. Li X, Tabil LG, Panigrahi S (2007) Chemical treatments of natural fiber for use in natural fiber-reinforced composites: a review. J Polym Environ 15 (1):25-33

8. Pickering K (2008) Properties and performance of natural-fibre composites. Elsevier, Cambridge England

9. Kabir MM, Wang H, Lau KT, Cardona F (2012) Chemical treatments on plant-based natural fibre reinforced polymer composites: An overview. Composites, Part B 43 (7):2883-2892

10. Sawpan MA, Pickering KL, Fernyhough AJ (2011) Effect of various chemical treatments on the fibre structure and tensile properties of industrial hemp fibres. Composites, Part A 42 (8):888-895

11. Xie Y, Hill CAS, Xiao Z, Militz H, Mai C (2010) Silane coupling agents used for natural fiber/polymer composites: A review. Composites, Part A 41 (7):806-819

12. Liu H, You L, Jin H, Yu W (2013) Influence of alkali treatment on the structure and properties of hemp fibers. Fibers Polym 14 (3):389-395

13. Chandrasekar M, Ishak M, Sapuan S, Leman Z, Jawaid MJ (2017) A review on the characterisation of natural fibres and their composites after alkali treatment and water absorption. Plastics, Rubber and Composites 46 (3):119-136

14. Manalo AC, Wani E, Zukarnain NA, Karunasena W, Lau K-tJ (2015) Effects of alkali treatment and elevated temperature on the mechanical properties of bamboo fibre-polyester composites. Composites, Part B 80:73-83

15. Keener T, Stuart R, Brown T (2004) Maleated coupling agents for natural fibre composites. Composites, Part A 35 (3):357-362

16. Prachayawarakorn J, Khunsumled S, Thongpin C, Kositchaiyong A, Sombatsompop N (2008) Effects of silane and MAPE coupling agents on the properties and interfacial adhesion of wood-filled PVC/LDPE blend. J Appl Polym Sci 108 (6):3523-3530

17. Cisneros-López EO, González-López ME, Pérez-Fonseca AA, González-Núñez R, Rodrigue D, Robledo-Ortíz JRJ (2017) Effect of fiber content and surface treatment on the mechanical properties of natural fiber composites produced by rotomolding. Compos Interfaces 24 (1):35-53

18. Hanana FE, Chimeni DY, Rodrigue DJ (2018) Morphology and mechanical properties of maple reinforced LLDPE produced by rotational moulding: Effect of fibre content and surface treatment. Polym Compos 26 (4):299-308 
19. M.M. Kabir $\Uparrow$ HW, K.T. Lau, F. Cardona (2012) Chemical treatments on plant-based natural fibre reinforced polymer composites.An overview. Composites: Part B 43:10

20. Mishra M (2018) Encyclopedia of Polymer Applications, 3 Volume Set. CRC Press,

21. Pickering KL, Efendy MA, Le TMJCPAAS, Manufacturing (2016) A review of recent developments in natural fibre composites and their mechanical performance. 83:98-112

22. Prime RB, Bair HE, Vyazovkin S, Gallagher PK, Riga A (2009) Thermogravimetric analysis (TGA). Thermal analysis of polymers: Fundamentals and applications. John Wiley \& Sons, Hoboken, NJ

23. Efendy MA, Pickering KLJ (2014) Comparison of harakeke with hemp fibre as a potential reinforcement in composites. Composites, Part A 67:259-267

24. Le Troedec M, Sedan D, Peyratout C, Bonnet JP, Smith A, Guinebretiere R, Gloaguen V, Krausz PJ (2008) Influence of various chemical treatments on the composition and structure of hemp fibres. Composites, Part A 39 (3):514-522

25. Kabir M, Wang H, Lau K, Cardona FJ (2013) Effects of chemical treatments on hemp fibre structure. Appl Surf Sci 276:13-23

26. Beckermann G (2007) Performance of hemp-fibre reinforced polypropylene composite materials. The University of Waikato,

27. Islam M, Pickering K, Foreman N, Manufacturing (2010) Influence of alkali treatment on the interfacial and physico-mechanical properties of industrial hemp fibre reinforced polylactic acid composites. Composites Part A: Applied Science 41 (5):596-603

28. Fan M, Naughton AJCPBE (2016) Mechanisms of thermal decomposition of natural fibre composites. 88:1-10

29. Kabir M, Wang H, Lau K, Cardona F (2012) Chemical treatments on plant-based natural fibre reinforced polymer composites: An overview. Composites, Part B 43 (7):2883-2892

30. Tomczak F, Satyanarayana KG, Sydenstricker THDJ (2007) Studies on lignocellulosic fibers of Brazil: Part III-Morphology and properties of Brazilian curauá fibers. Composites, Part A 38 (10):2227-2236

31. Kabir M, Wang H, Lau K, Cardona F, Aravinthan T (2012) Mechanical properties of chemically-treated hemp fibre reinforced sandwich composites. Composites, Part B 43 (2):159169

32. Sgriccia N, Hawley M, Misra M (2008) Characterisation of natural fiber surfaces and natural fiber composites. Composites, Part A 39 (10):1632-1637

33. Shahzad AJJoCM (2012) Hemp fiber and its composites-a review. 46 (8):973-986 
34. Sawpan MA, Pickering KL, Fernyhough A Hemp fibre reinforced poly (lactic acid) composites. In: Advanced Materials Research, 2007. Trans Tech Publ, pp 337-340

35. Saheb DN, Jog JPJAiPTJotPPI (1999) Natural fiber polymer composites: a review. 18 (4):351-363

36. Ortega Z, Monzón M, Benítez A, Kearns M, McCourt M, Hornsby PJ (2013) Banana and abaca fiber-reinforced plastic composites obtained by rotational molding process. Mater Manuf Processes 28 (8):879-883

37. Verdaguer A, Rodrigue D Effect of surface treatment on the mechanical properties of wood-plastics composites produced by dry-blending. In: Proceedings of the 72th Annual Technical Conference \& Exhibition, 2014. Society of Plastics Engineers Las Vegas NV, pp 2830

38. Torres FG, Aragon CL (2006) Final product testing of rotational moulded natural fibrereinforced polyethylene. Polym Test 25 (4):568-577

39. Keener T, Stuart R, Brown TJCPAas, manufacturing (2004) Maleated coupling agents for natural fibre composites. 35 (3):357-362

40. Yang H-S, Wolcott MP, Kim H-S, Kim S, Kim H-JJCS (2007) Effect of different compatibilizing agents on the mechanical properties of lignocellulosic material filled polyethylene bio-composites. 79 (3):369-375

\section{Figures}

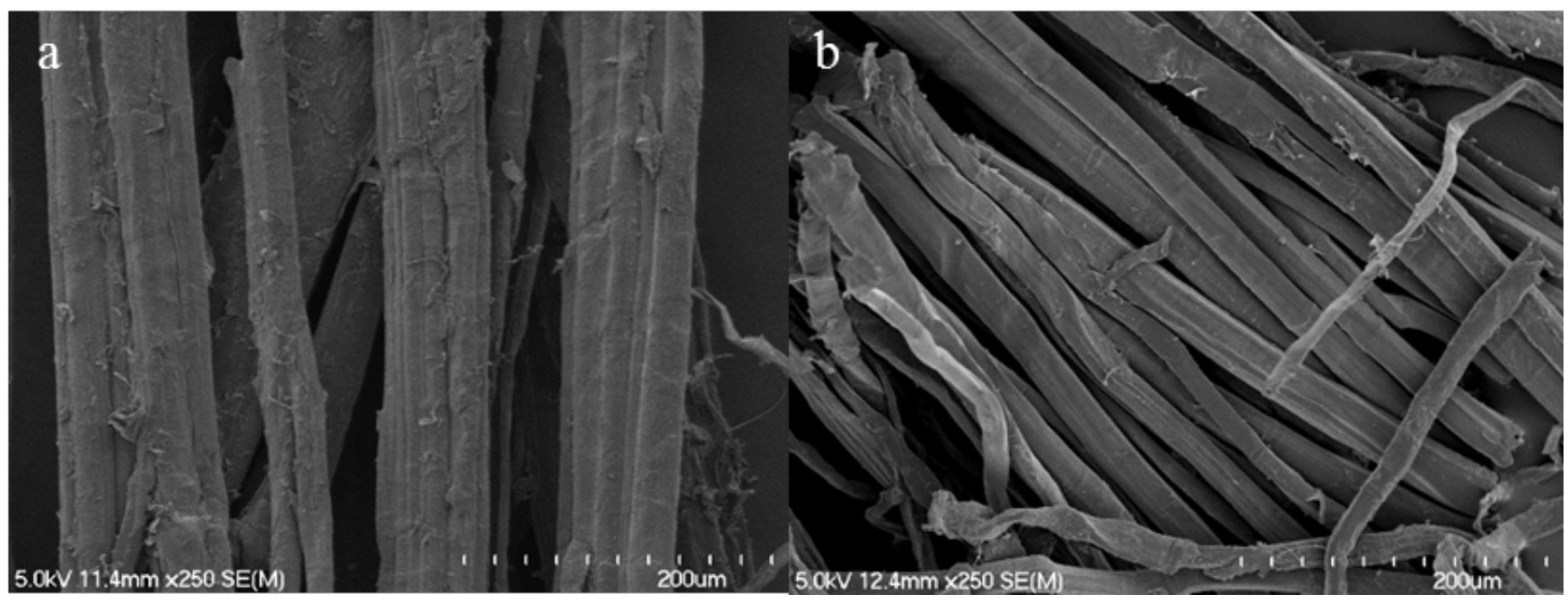

Fig. 1 SEM micrograph of untreated (a) and alkali-treated hemp fibre (b) 


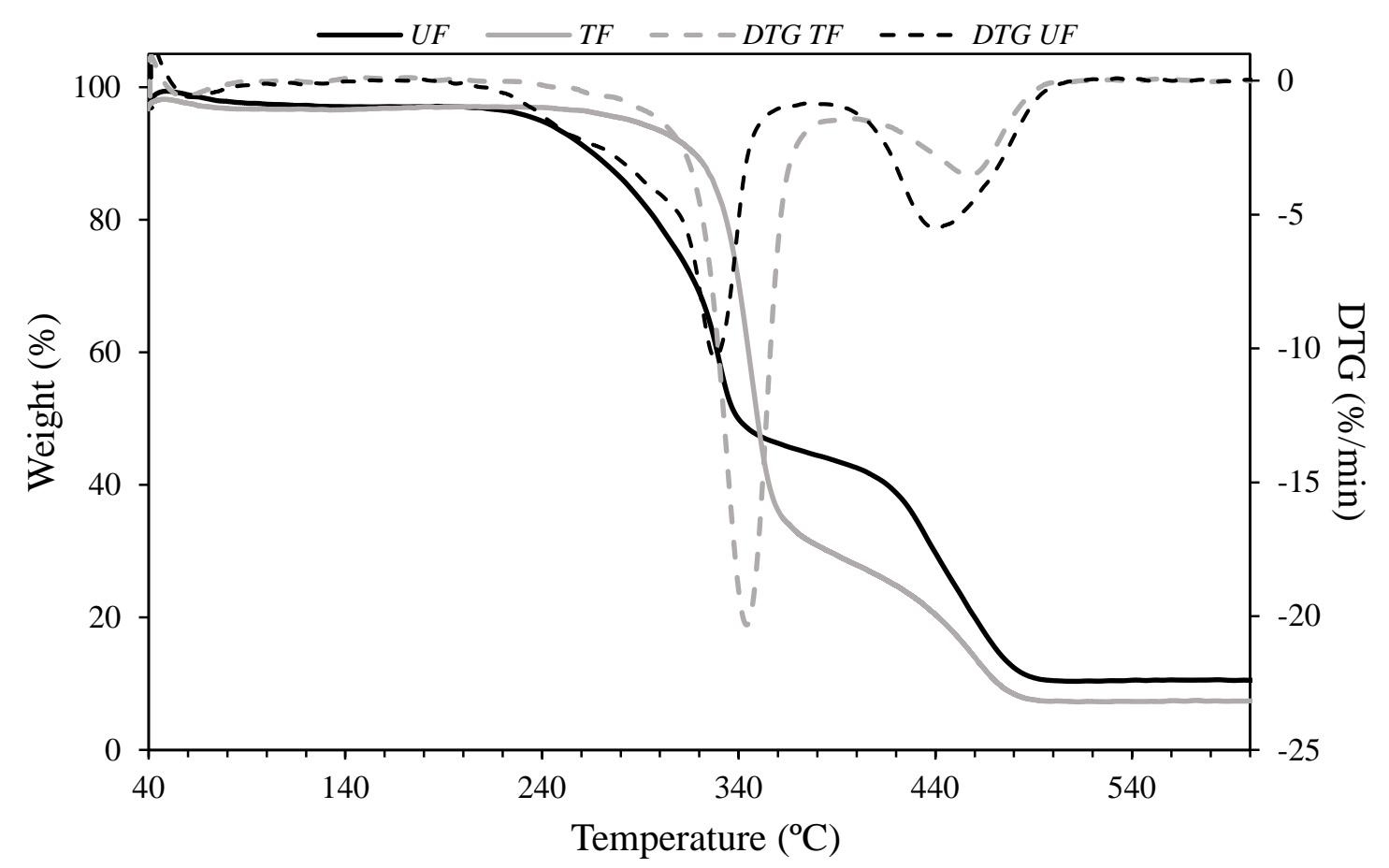

Fig. 2 TGA and DTG thermograms of untreated (UF) and alkali-treated hemp fibre (TF). 


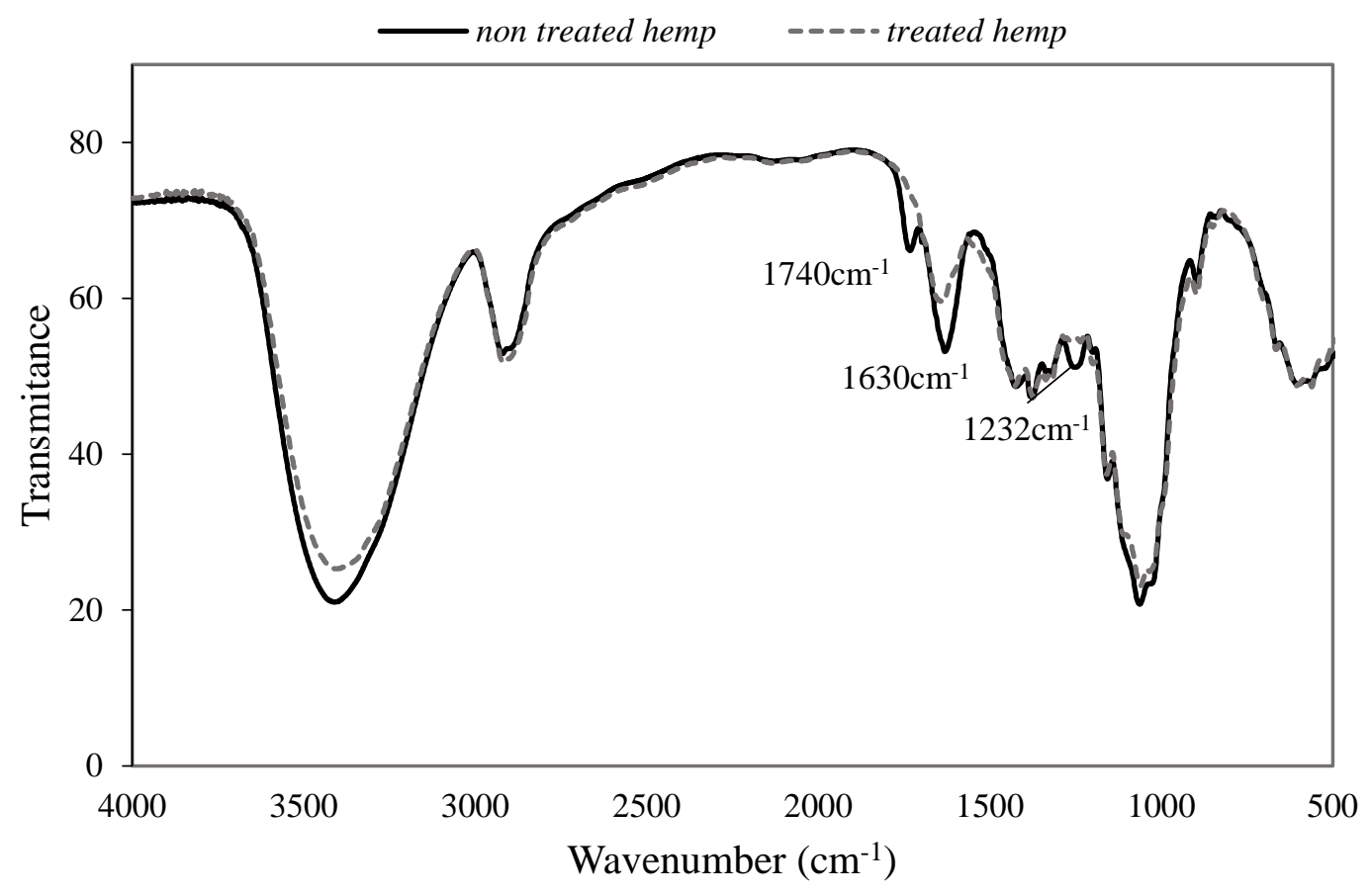

Fig. 3 FT-IR spectra of untreated and alkali-treated hemp fibre.

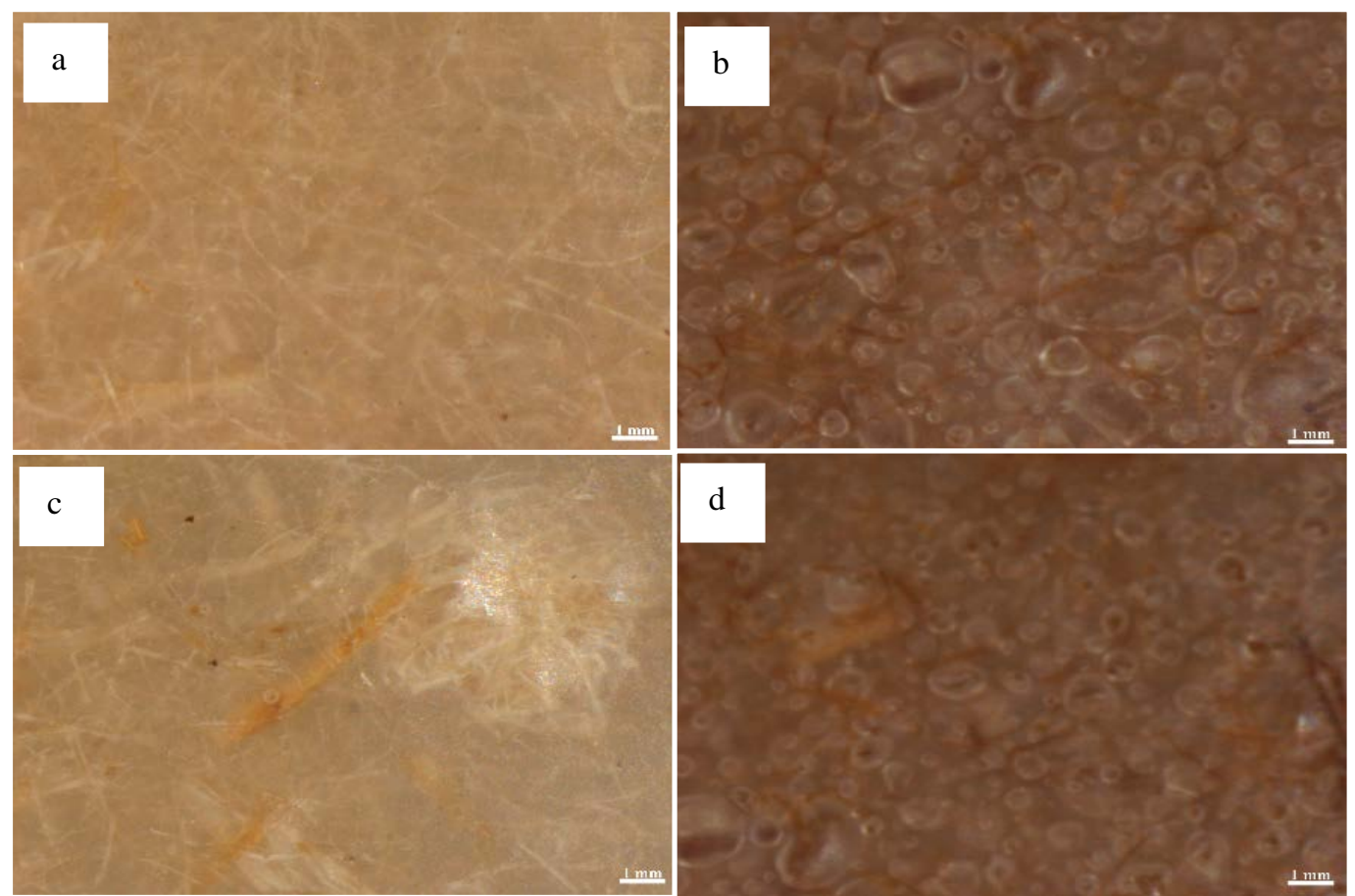

Fig. 4 Optical microscopy images of rotationally moulded PE composites. 5TM (a), 5U (b), 5T(c) and 5UM (d) (T = treated hemp; U= untreated hemp, $\mathrm{M}=$ MAPE) 

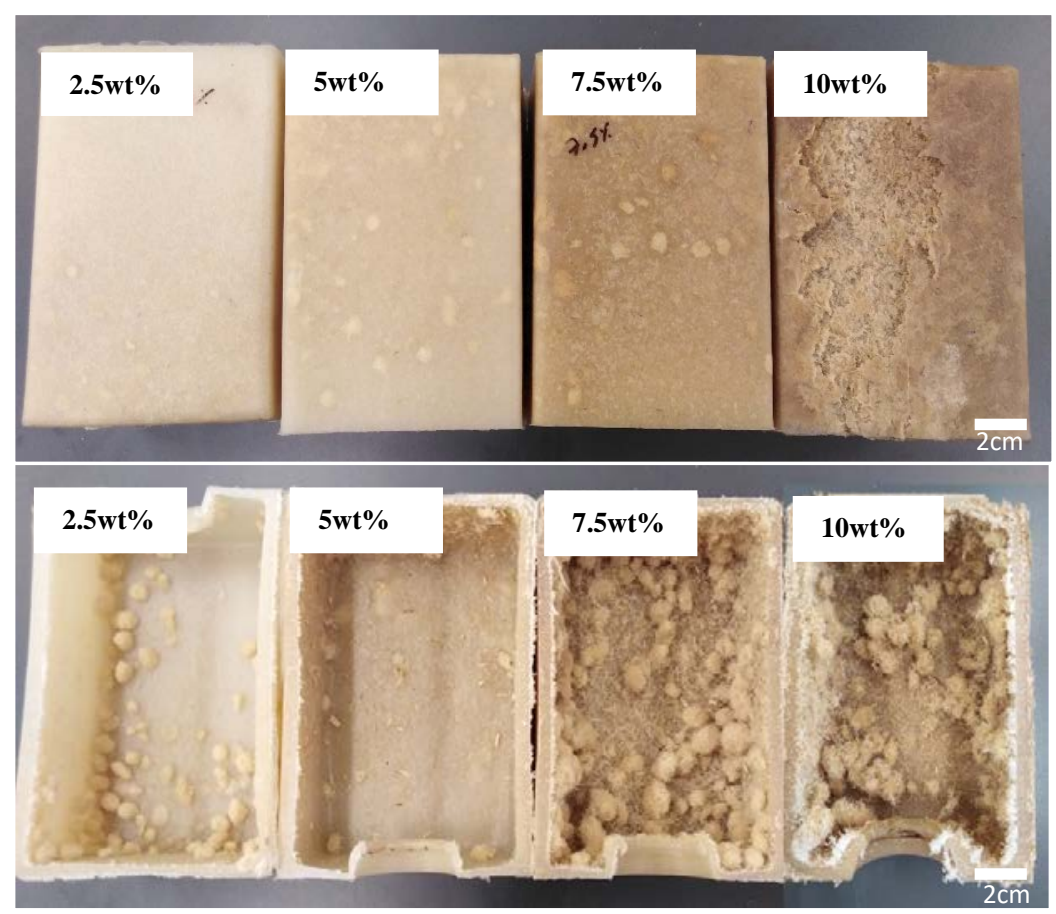

Fig. 5 Rotationally moulded PE composites: 2.5TM, 5TM, 7.5TM and 10TM (T= treated hemp, M=MAPE) from left to right, showing outer (upper row) and inner (lower row) surfaces
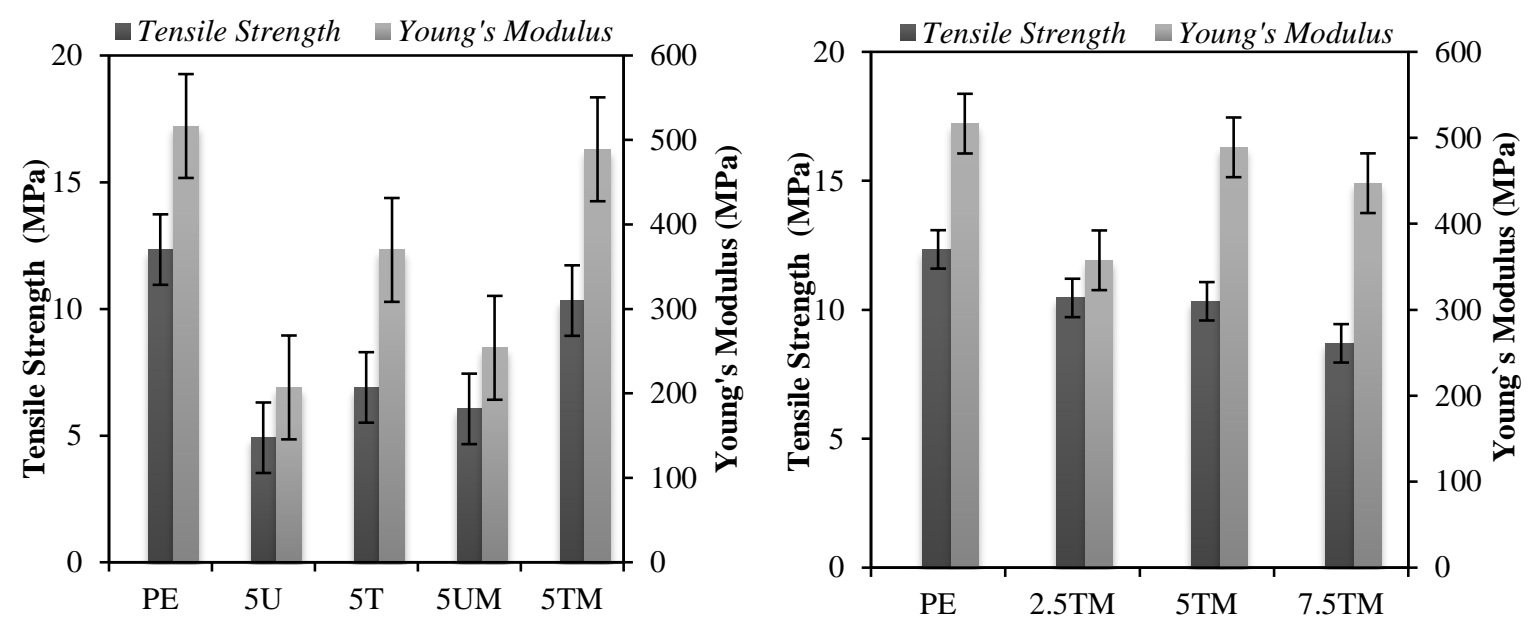

Fig. 6: Tensile strength and Young's modulus of rotationally moulded PE composites, samples: PE, 5U, 5T, 5UM and 5TM, 2.5TM and 7.5TM. The code means: fibre content, $\mathrm{T}=$ treated hemp; $\mathrm{U}=$ untreated hemp, $\mathrm{M}=\mathrm{MAPE}, \mathrm{PE}=$ polyethylene. 


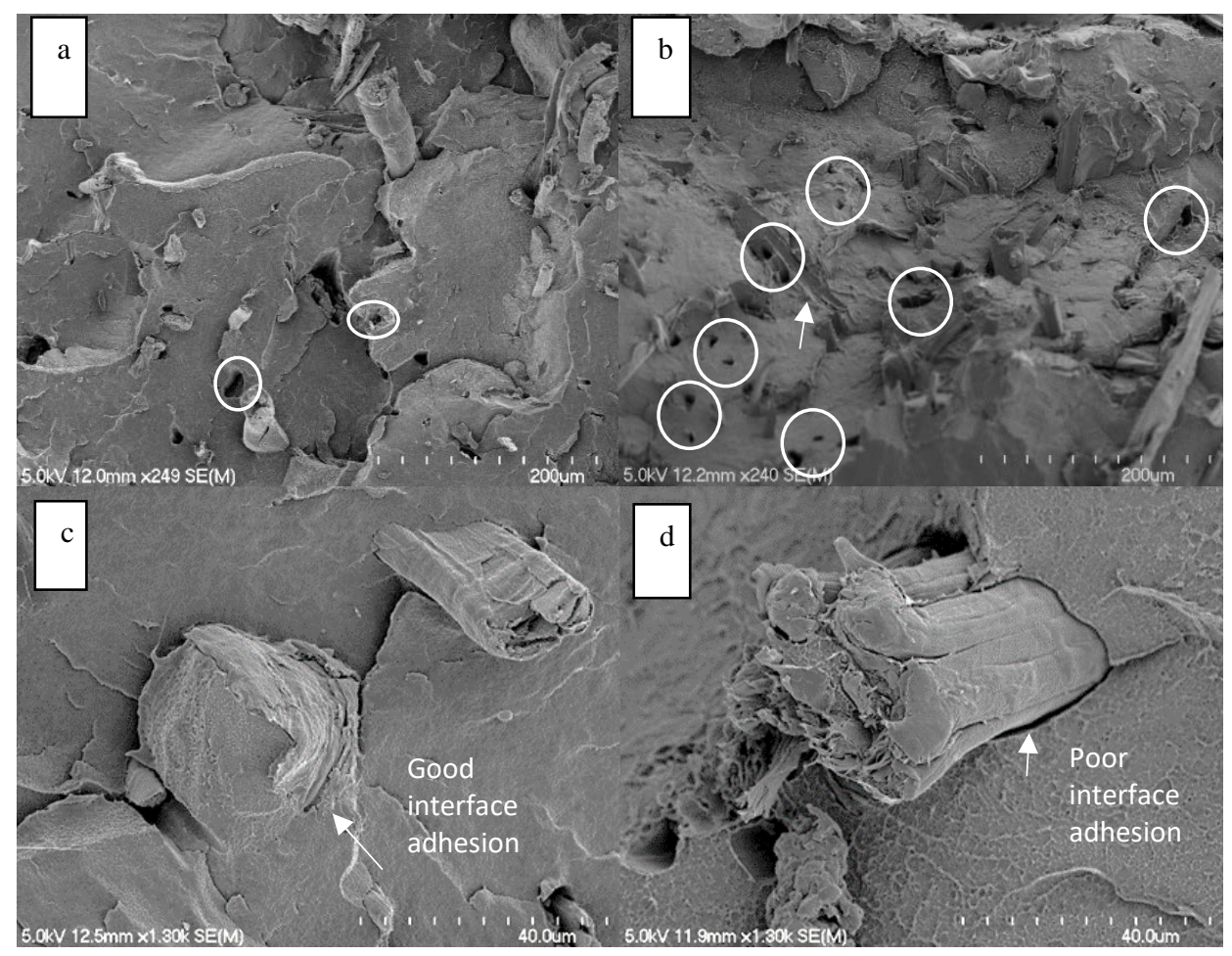

Fig.7 SEM micrographs of cryogenic fracture surfaces of samples: 5TM (a and c) and 5T (b and d) ( $\mathrm{T}$ = treated hemp; $\mathrm{M}=\mathrm{MAPE})$ 
Table 1: Composition of rotationally moulded composites.

\begin{tabular}{|c|c|}
\hline Sample & Composition \\
\hline $2.5 \mathrm{TM}$ & 2.5 wt\% Treated Hemp Fibre - 3 wt\% MAPE - 94.5 wt\% PE powder \\
\hline 5TM & 5 wt $\%$ Treated Hemp Fibre - 3 wt\% MAPE - 92 wt\% PE powder \\
\hline 7TM & 7 wt $\%$ Treated Hemp Fibre - 3 wt\% MAPE - 90 wt $\%$ PE powder \\
\hline 5UM & 5 wt $\%$ Untreated Hemp Fibre - 3 wt\% MAPE - 92 wt\% PE powder \\
\hline $5 \mathrm{~T}$ & 5 wt\% Treated Hemp Fibre - 95 wt\% PE powder \\
\hline $5 U$ & 5 wt\% Untreated Hemp Fibre - 95 wt\% PE powder \\
\hline $\mathrm{PE}$ & $100 \mathrm{wt} \%$ LMDPE powder \\
\hline \multicolumn{2}{|r|}{ The samples were named according to the following scheme: Fibre content (wt \%), } \\
\hline & $\mathrm{T}=$ treated hemp; $\mathrm{U}=$ untreated hemp, $\mathrm{M}=\mathrm{MAPE}, \mathrm{PE}=$ polyethylene \\
\hline
\end{tabular}

Table 2: The average of diameter and tensile strength of untreated and alkali treated hemp fibre (Standard deviation is in parentheses).

\begin{tabular}{c|cc}
\hline Fibre treatment & Fibre diameter ( $\mu m)$ & Tensile Strength (MPa) \\
\hline Untreated & $29(11)$ & $715(471)$ \\
$\mathrm{NaOH} / \mathrm{Na}_{2} \mathrm{SO}_{3}$ & $22(8)$ & $703(412)$ \\
\hline
\end{tabular}

